\title{
Strategic forecasting of REE mining projects development in Russian Arctic
}

\author{
V.M. Solovyova \\ Postgraduate student, Department of Organization and Management, Saint-Petersburg Mining University, \\ Saint-Petersburg, Russia
}

\begin{abstract}
A.A. Ilinova
Candidate of Economic Sciences, Associate Professor, Department of Organization and Management, Saint-Petersburg Mining University, Saint-Petersburg, Russia
\end{abstract}

\author{
A.E. Cherepovitsyn \\ Doctor of Economic Sciences, Professor, Department of Organization and Management, Saint-Petersburg \\ Mining University, Saint-Petersburg, Russia
}

\begin{abstract}
To date, issues related to the effective development of mineral and raw material base are becoming increasingly important especially for Arctic zone. Particular attention is paid to expanding the possibility of the integrated use of mineral deposits in order to extract rare-earth components. Currently, a significant deficit has formed in these elements, however, the prospects for the domestic REE industry's development remain uncertain. It determines the relevance of the topic. This paper deals with the investigation of possibilities for REE mining projects development strategic forecasting. The overview of national and global rare earth market is presented. Strategic importance of REE projects implementation for Russia is discussed. Existing strengths, weaknesses, threats and opportunities of REE mining industry projects in Russian Arctic with the aid of SWOT-analysis are identified. Decomposition of factors determining uncertainty of rare earth projects forecasts is presented. The study makes a number of recommendations aimed at the creation of strategic forecasting system of REE industry development in Russia.
\end{abstract}

\section{INTRODUCTION}

In recent years, there has been an increasing interest in the development of Russian Arctic mineral resources (Larichkin 2008; Dmitrieva \& Ilinova 2017). However, existing challenges related to the low rate of recourses reproduction, gradual depletion of mineral base, low probability of novel deposits identification with huge amount of high-quality reserves were the causes of formed deficit in rare earth elements (REE) in the national market (Larichkin 2011). According to statistical data, the need for REE at the side of Russian industrial complex seven times more than the volume of national production (Scripachev 2018). Obviously, it leads to the increase in import dependence of national high tech industries.

Despite the great potential of rare earth elements mineral base in Arctic Zone, rare earth elements mining industry projects aren't been implemented in Russia. The prospects of REE industry projects development stay undetermined. To overcome this uncertainty it's necessary to identify what kind of rare earth elements have critical importance, analyze market trends (supply, demand on certain types of elements), investigate prospective projects, and evaluate existing threats and opportunities. It's required the formation of special system within strategic forecasting that allows to take into account the specific features of REE mining industry projects implementation. 
This paper attempts to show that the development of rare earth industry both strategic and one of the most complicated direction. The objectives of this research are to investigate existing trends within national REE industry, to determine factors influenced the rare earth elements projects development and discuss specific features of these projects.

\section{LITERATURE REVIEW}

The existing literature on the aspects of complex use of mineral raw materials in Russian Arctic is extensive (Ponomarenko et al. 2018; Cherepovirsyn et al. 2018; Nevskaya 2019). The efficiency of mineral and raw materials base's development is related to the possibilities of rational subsoil use and opportunities in the sphere of extraction and processing of worth components, including REEs (Nedosekin 2019; Ponomarenko et al. 2019).

There is a large volume of published studies describing the role of rare earth elements in modern global economics (Wall 2014; Charalampides et al. 2015; Eggert et al. 2016; Zhou et al. 2017; Ganguli 2018; Balaram 2019). Much of the current literature on REE market pays particular attention to analyses of available resource potential (Saveleva 2011; Paulick \& Machacek 2017), determination of technological accessibility (Takeda \& Okabe 2014; Anderson 2016), investigation for global market conditions (Nassar et al. 2015; Alvin 2018).

The existing foreign literature focuses particularly on the forecasting of REE industry development (Goodenough et al. 2017; Fernandez 2017). Most researchers investigating this sphere have utilised methods and instruments of strategic analyses (Chen 2011; Kalvig \& Machacek 2016). Using these instruments, researchers have been able to make medium- and long-term quantitative forecasts taking into account reliable trends of global market.

Nevertheless, there is a relatively small body of national literature that is concerned with forecasting trends of Russian REE industry development. A number of studies have begun to examine main prospects of this industrial branch (Postolateva et al. 2013; Novikov \& Salikhov 2015; Glushchenko et al. 2017; Scripachev 2018). However, such studies remain narrow in focus dealing only with certain aspects of industrial potential and focus on common directions of future development.

In Russia special document devoted to REE industry development is established («The development Strategy of the rare and rare earth metals industry of the Russian Federation for the period up to 2035»). However, most of document provisions are theoretical, the directions of future industrial development are not determined, the prospects stay uncertain.

Thus, despite the range of existing papers devoted to different aspects of rare earth market, there are no publications devoted to strategic forecasting of REE mining industry projects in Russian Arctic.

\section{METHODOLOGY}

The study uses qualitative analysis in order to gain insights into main directions within analysis of REE global and national market, investigation of foreign critical materials concepts (Massari \& Ruberti 2013). Key features of the rare earth projects development were studied on the basis of scientific works of Russian and foreign researchers (Novikov \& Salikhov 2015; Glushchenko et al. 2017; Goodenough et al. 2017; Fernandez 2017, et al.).

A strategic method - SWOT analysis - was used to allow a deeper insight into prevailing conditions of REE industry development in Russia. The benefit of this instrument is that it allows to identify strengths, weaknesses, opportunities and threats related to selected object of study. However, there are certain drawbacks associated with the use of offered method, as it does not permit to take into account specific factors connected with REE projects development. Therefore, application of this method was complemented by the decomposition of factors determining uncertainty of forecasts.

The legal basis of the study is formed by analyzing the Federal Law «On Subsoil», the «Strategy of development of mineral resources base of the Russian Federation till 2035», «The 
development Strategy of the rare and rare earth metals industry of the Russian Federation for the period up to 2035 », et al.

The methods collectively used in the study made it possible to ensure the reliability and validity of the conclusions.

\section{RESULTS}

\subsection{Market overview}

Rare-earth metals are among the types of minerals that are of strategic importance to all developed countries in the world. Global market of REE is growing rapidly. Its volume increased by more than 25 times (from 5 thousand tons to 125 thousand tons per year) over the last ten years (Samsonov \& Semyagin 2014). Main global consumers of rare earth elements are Japanese (approximately 60\%) and Malaysia (about 23\%). The leader in the production of REE in the world market remains China (more than $90 \%$ of global market) (Paulick \& Machacek 2017; Rare earth market outlook: supply, demand, and pricing from 2016 through 2025).

Today the opportunities of high-tech sectors are associated with the development of REE industrial potential (Future Supply of Rare Earth Elements). In Russia the largest share in the structure of rare earth elements consumption is occupied by the production of catalysts, metallurgy, glass production (Figure 1).

Although the great opportunities within significant mineral and raw materials base, the national REE industry remains poorly developed. Russian share of REE supply in the global market not exceed the values of $2 \%$.

Nowadays, the production of certain types of rare earth elements is carried out by three companies: JSC Solikamsk Magnesium Works (carbonates), Acron Group (cerium and lanthanum oxides) and The Laboratory of Innovative Technologies - «LIT» (cerium, neodymium, lanthanum and lanthanum oxides) (Scripachev 2018). According to the «Development Strategy of the rare and rare earth metals industry of the Russian Federation for the period up to 2035», there are a range of prospective REE projects including Integrated Chemical and Metallurgical Complex «African Project», Tomtor rare metal deposit (Burany site) in the Republic of Sakha (Yakutia), Development of germanium-containing lignite deposit in Krasnoyarsk, et al. Nevertheless, the prospects of these projects implementation remain unclear today.

The annual volume of REE national market increased sharply between 2017 and 2018 with the rate of growth $31,3 \%$ (Figure 2). The major of required elements (more than $80 \%$ ) are imported from China, Estonia, Austria, et al. On the one hand, it allows to ensure national

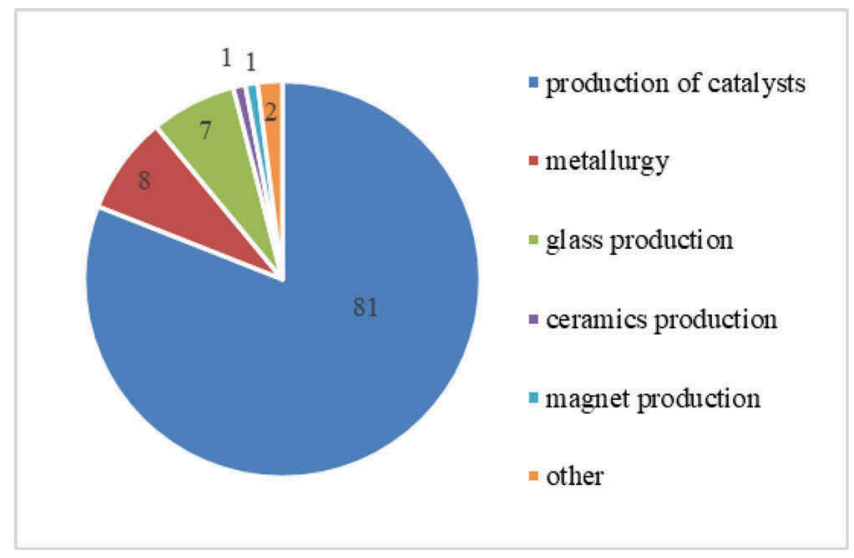

Figure 1. Structure of REE consumption in Russia, \% (2018) (Scripachev 2018). 


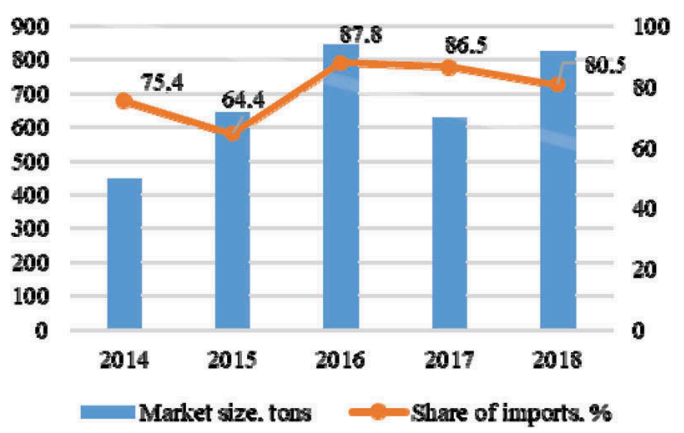

Figure 2. Market size of national REE market 2014-2018 (Scripachev 2018; Alvin 2018).

industry with rare earth elements. On the other hand, import dependence is increasing, that can influence the sustainability of strategic industrial branches including military complex, oil and gas machinery, et al.

In medium term, it's expected the increase in domestic demand for REE. Possible directions of prospective growth in production volumes of rare earth elements are the following:

- Volume of catalysts production is on the increase. New capacities for the manufacture of catalysts are established at Gaspromneft - Catalytic Systems LLC production site.

- Development of aircraft engines industry (PD-14, PD-35).

- Development of the production gas turbine engine, marine gas turbine engine.

- Expanding the use of rare-earth metals as burnable additives in uranium oxide fuel from VVER and RBMK reactors.

- Construction of the neodymium versatate production with a capacity of 120 tons per year at the site of JSC Voronezhsintezkauchuk, et al.

At present, main priorities within development of national REE industry include satisfaction of the needs of defense industry enterprises with domestic rare earth metals, ensuring national consumption of REE with its further growth and reduction in the share of imports to a minimum level (import substitution), increase in export potential.

\subsection{Forecasting of REE mining projects development}

Nowadays the reduction in level of import substitution within REE industry is relevant direction. Thus, it's necessary to remove existing barriers connected with REE industry development in Russia. To achieve this aim it's required the formation of complex planning and forecasting systems. The first step must be to determine specific factors of rare earth elements projects and aspects influenced their development and implementation.

As it was mentioned before, in Russia there are significant reserves of rare earth metals. The technologies for the extraction of individual elements are available. The legal and regulatory conditions are being improved (Solovyova \& Cherepovitsyn 2019). However, along these «strengths» there is a range of negative factors. They include high cost of extracting worth components, lack of special instruments to support REE projects, imperfection of legal regulation of the development of the rare earth metals industry in the country, et al.

Globally, the REE market is monopolized. Thus, the main external risk is the strengthening of the competitive position of foreign manufacturing companies in the national market. This risk comes down to the supply of cheaper REE products, which can lead to unprofitable development of new deposits and a drop in demand for domestic REE. Internal risks are directly related to instability of demand for REE (lack of long-term contracts), lack of consumer interest in the supply of national REE products. Moreover, the process of replacing traditionally used materials (metals and alloys) with new materials based on REE can be long-term.

Main strengths, weaknesses, opportunities and threats of REE mining industry projects in Russian Arctic have been determined. The results in Table 1 are shown. 
Table 1. SWOT analysis of REE mining projects development in Russian Arctic.

\begin{tabular}{|c|c|}
\hline Strengths & Weaknesses \\
\hline $\begin{array}{l}\text { - significant reserves of rare-earth metals in Russian } \\
\text { Arctic (large mineral resource base); } \\
\text { - high quality of mineral resources; } \\
\text { - possibility of involving technogenic deposits in } \\
\text { order to extract individual components; } \\
\text { - availability of technologies for the extraction of } \\
\text { individual components of rare-earth metals; } \\
\text { - development of REE projects on the basis of the } \\
\text { existing mining enterprises }\end{array}$ & $\begin{array}{l}\text { - lack of geological data (necessity of additional } \\
\text { exploration); } \\
\text { - high cost of extracting worth components; } \\
\text { - remote location of REE deposits; } \\
\text { - lack of special instruments to support REE } \\
\text { projects; } \\
\text { - lack of experience of REE projects } \\
\text { implementation; } \\
\text { - absence of the strategic planning system that allows } \\
\text { to determine the forecasts of certain REE projects }\end{array}$ \\
\hline Opportunities & 1月10 \\
\hline $\begin{array}{l}\text { - expansion of the use of rare-earth elements } \\
\text { (growth in domestic and global demand); } \\
\text { - increasing demand for rare-earth metals in the } \\
\text { production of steel, metals and alloys; } \\
\text { - presence of trends in price levels for most types of } \\
\text { rare-earth elements; } \\
\text { - development of enrichment technologies in order } \\
\text { to extract valuable components of mineral raw } \\
\text { materials (integrated use of mineral raw } \\
\text { materials); } \\
\text { - development of import substitution policy; } \\
\text { - creation of special industrial and raw material } \\
\text { centers for the development of projects; } \\
\text { - establishment of tax benefits on mineral extraction } \\
\text { for rare earth metals (in } 2020 \text {, the tax rate was } \\
\text { reduced from } 8 \% \text { to } 4.8 \% \text { ); } \\
\text { - adoption of the development Strategy of the rare } \\
\text { and rare earth metals industry }\end{array}$ & $\begin{array}{l}\text { - high risks of changes in market; } \\
\text { - slowdown in the growth of national high-tech } \\
\text { industries; } \\
\text { - long-term process of replacing traditionally used } \\
\text { materials (metals and alloys) with new materials } \\
\text { based on REE; } \\
\text { - monopolized market at the world level (more than } \\
\text { 90\% of supplies are made by China); } \\
\text { - high level of competition in the national market at } \\
\text { the side of foreign companies; } \\
\text { - imperfection of legal regulation of the develop- } \\
\text { ment of the rare earth metals industry in the } \\
\text { country; } \\
\text { - lack of incentives for subsoil users (economic, } \\
\text { administrative, financial) to implement projects; } \\
\text { - strengthening import substitution strategies in } \\
\text { Europe (critical materials) }\end{array}$ \\
\hline
\end{tabular}

According to the obtained results, one of the most significant factors restraining the development opportunities of the industry is a high degree of uncertainty and the impossibility of its reduction as there are no special methods and instruments allow to forecast future prospects of REE projects implementation. It's critical to understand that REE projects have their specific features that must be taken into account within formation the directions of future development.

Key features of these projects implementation are the following:

1. Geological uncertainty;

2. Market uncertainty;

3. Uniqueness of each REE deposit and characteristics of ore reserves (unique location, content of commercial components and their distribution, which determines different mining rent);

4. Gradual depletion of resources;

5. Capital-intensive and long-term development of the projects;

6. Geographical attachment of production to mining sites (reduced flexibility compared to the other types of industries; geographical distance and underdeveloped infrastructure, entailing additional investment), etc.

Thus, making forecasts regarding the prospects for implementing REE projects, scientists may encounter the following difficulties: lack of reliable data related to geological information, possible volume of production, et al.; need for taking into account and linking a range of 


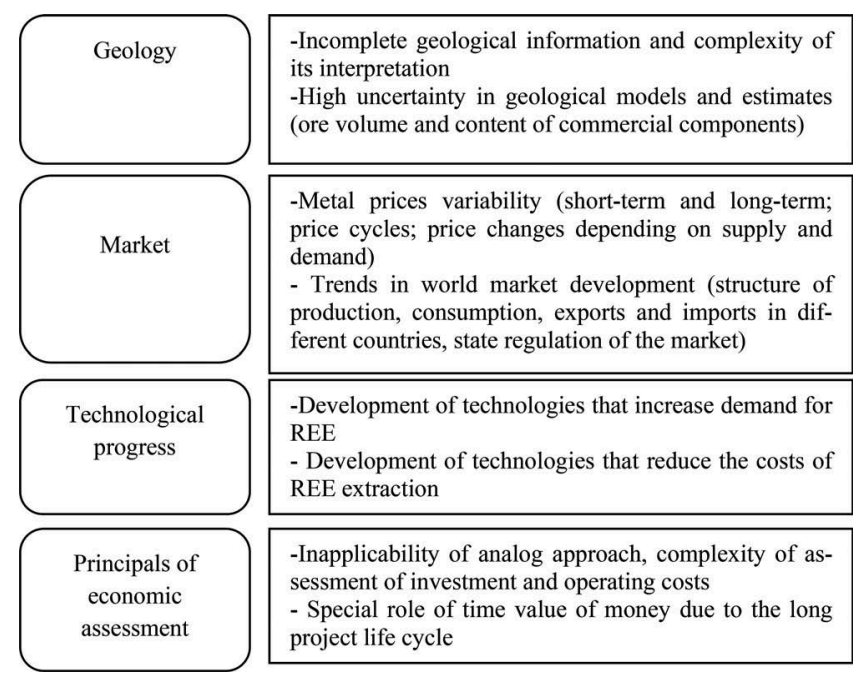

Figure 3. Decomposition of factors determining uncertainty of forecasts.

different specific factors related to REE projects implementation; uniqueness of each project; necessity for combining business interests with strategic priorities of the national REE industry.

All listed above determines the peculiarities of forecasting the development of REE projects. As it was noted, the need for REE in Russia is obvious, but the prospects for such projects remain unclear today. A high degree of uncertainty is associated with the influence of a range of factors, which together create a difficult predictable situation.

Figure 3 shows the decomposition of key factors that create uncertainty in forecasting of REE projects development in the Arctic.

Identified factors include geology, market, technological progress and principals of economic assessment. To reduce the existing uncertainty, it is necessary to explore each of the given parameters and take into consideration the factors and features of REE projects that has been discussed.

To create and establish strategic forecasts regarding the development of the national rareearth industry, the following recommendations are necessary:

1. Updating the list of strategically significant types of mineral raw materials;

2. Study of market parameters for each type of rare earth metals (national and world market) using tools and methods of strategic analysis;

3. The establishment of strategic priorities for the development of the industry, the selection of development objects, the formation of a critical technologies list;

4. Formation of special mineral resource centers for the development of certain areas of the rare earth industry;

5. Creation of a methodological base for planning and forecasting complex industrial systems;

6. Formation of a controlled development parameters system of individual complexes taking into consideration the specifics of REE projects.

\section{DISCUSSION}

The findings of this study suggest that the rare earth elements projects implementation is significant direction within strategic development of Russian industrial complex and economics. Obviously, in the medium term, it is necessary to solve the emerging problem of high import dependence on supplies of products from foreign countries. 


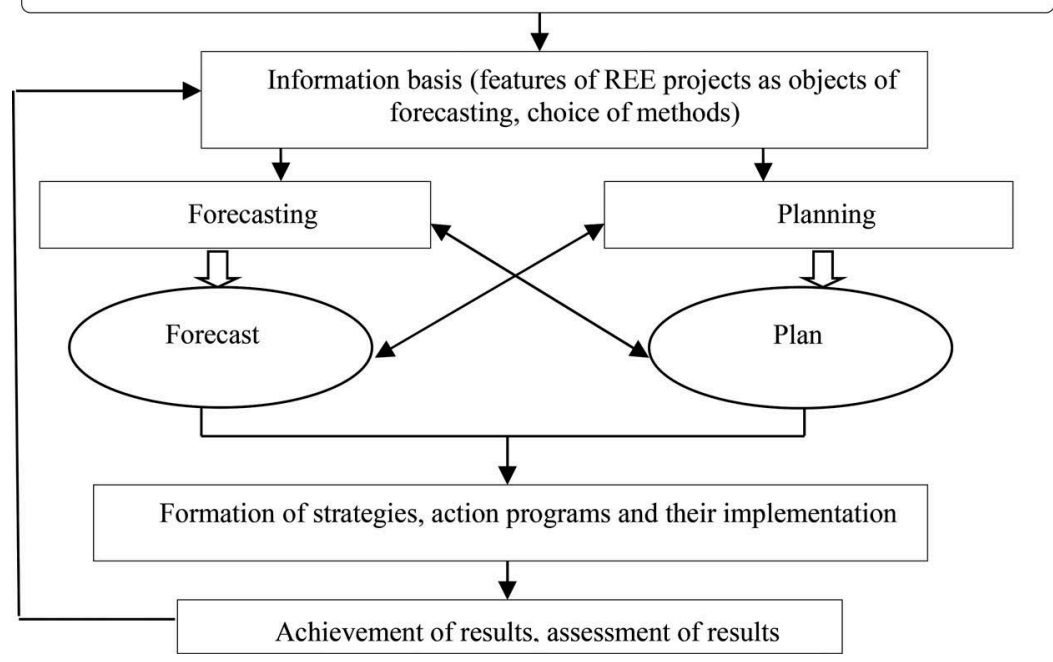

Figure 4. The algorithm of strategic management system.

Rare earth industry is a part of mining industry. However, it has significant specific features that must be taken in consideration. Despite the urgency of the problem of the domestic rare earth industry development, the real prospects remain uncertain. It is unclear what projects will be implemented in the future, whether there will be a demand for domestic rare-earth elements from Russian consumers, what will be the volume of the domestic market in the medium term, etc. That is why it is critically important to forecast the prospects of industry development despite the high level of uncertainty. The forecasting process is closely interconnected with planning. Based on forecasts, specific plans are formed containing a list of activities necessary to achieve the goals and objectives, as well as criteria, indicators and performance indicators for their implementation. The algorithm of strategic management system of REE industry development is presented in Figure 4.

The results of this study related to the features of REE projects and key criteria allow to form an information basis for future research. The study presents factors determining uncertainty of REE projects development forecasts. Based on these factors, it is planned to develop specific indicators, the calculation of which will allow to form conclusions regarding the development of individual projects and the industry as a whole.

The determined features of forecasting the implementation of rare earth elements projects will be taken into account within development of special methodological approaches to forecasting and planning. The findings of this study have a number of important implications for future practice.

\section{CONCLUSION}

The Arctic region of the Russian Federation is essential for the whole country because of its unique mineral raw material base. Obviously, efficient development of the Arctic zone resource potential is one of the strategic priorities for Russia. That goes also for development of rare earth elements resource base.

This paper has argued that development of national REE industry is of strategic importance. The efficiency of rare earth industrial potential realization determines the future of high-tech branches. However, the prospects of REE projects implementation remain unclear today. 
This study has identified key trends of national and global REE markets. The investigation has presented SWOT analysis of REE mining projects development. Key strengths, weaknesses, opportunities and threats have been determined.

The investigation has identified the features of rare earth elements projects implementation in Russian Arctic. They include uniqueness of each REE deposit and characteristics of ore reserves, geographical attachment of production to mining sites, market uncertainty, etc. Key factors creating uncertainty in forecasting of REE projects development in the Arctic have been formed. The study has made also a number of recommendations aimed at creation of strategic forecasts regarding the development of the national rare-earth industry. The results achieved will form the basis for formation of strategic forecasting system of REE projects development.

\section{ACKNOWLEDGEMENTS}

The research was carried out with the financial support of the Russian Science Foundation, the project "Strategic forecasting of development of industrial and mineral resources centers in the Arctic" No. 19-78-00108.

\section{REFERENCES}

Alvin, M.A. 2018. Rare Earth Elements Extraction \& Recovery: Research, Development, Demonstration and Deployment \& Market Outlook National Association of State Energy Officials (NASEO) Houston, TX.

Anderson, C. et al.2016. Rare Earth Recycling Opportunities Institute of Scrap Recycling Industries Annual Meeting April 6, 2016-Las Vegas, Nevada.

Balaram, V. 2019. Rare earth elements: A review of applications, occurrence, exploration, analysis, recycling, and environmental impact Geoscience Frontiers 10(4): 285-1303.

Charalampides, G. et al.2015. Rare Earth Elements: Industrial Applications and Economic Dependency of Europe Procedia Economics and Finance 24: 126-135.

Chen, Z. 2011. Global Rare Earth Resources and Scenarios of Future Rare Earth Industry Journal of Rare Earths 29(1): 1-6.

Cherepovitsyn, A.E., Lipina, S.A. \& Evseeva, O.O. 2018. An innovative approach to the development of the mineral resource potential of the Arctic zone of the Russian Federation Journal of Mining institute 232: $438-444$.

Dmitrieva, D.M. \& Ilinova, A.A. 2017. Development of the Russian Arctic zone: The role of innovation infrastructure and legal regulation International Journal of Applied Engineering Research 12 (19): 8179-8187.

Eggert, R. et al.2016. Rare earths: Market disruption, innovation, and global supply chains Annual Review of Environment and Resources 41: 199-222.

Fernandez, V. 2017. Rare-earth elements market: A historical and financial perspective Resources Policy 53: 26-45.

Future Supply of Rare Earth Elements. Overview. IPC. viewed 17.02.2020 http://www.ipc.org/Content Page.aspx?pageid=future-supply-of-rare-earth-elements.

Ganguli, R. \& Cook, D.R. 2018. Rare earths: A review of the landscape MRS Energy \& Sustainability: A Review Journal 5(e9): 1-16.

Glushchenko, Y.G., Nechaev, A.V. \& Polyakov, E.G. 2017. Development trends of the rare-earth industry in the Russian Federation Theoretical Foundations of Chemical Engineering 51(5): 835-840.

Goodenough, K.M., Wall, F. \& Merriman, D. 2017. The Rare Earth Elements: Demand, Global Resources, and Challenges for Resourcing Future Generations Natural Resources Research doi: 10.1007/s11053-017-9336-5.

Ilinova, A.A. \& Dmitrieva, D.M. 2018. The mechanism of innovative development of the Russian arctic zone International Journal of Mechanical Engineering and Technology 9(9): 1439-1451.

Kalvig, P. \& Machacek, E. 2016. Examining the rare-earth elements (REE) supply-demand balance for future global wind power scenarios Geological Survey of Denmark and Greenland Bulletin 41: 87-90.

Larichkin, F.D. 2008. Mineral Resources in the Russian Economy Journal of Mining Institute 179: 9-13.

Larichkin, F.D. 2011. Problems of study and rational development of mineral resources of the North and the Arctic Kola Scientific Center of the Russian Academy of Sciences 15-23. 
Massari, S. \& Ruberti, M. 2013. Rare earth elements as critical raw materials: Focus on international markets and future strategies Resources Policy 38(1): 36-43.

Nassar, N., Xiaoyue, D \& Graedel, T. 2015. Criticality of the Rare Earth Elements Journal of Industrial Ecology 19(6): 1044-1054.

Nedosekin, A.O., Rejshahrit, E.I. \& Kozlovskij, A.N. 2019. Strategic Approach to Assessing Economic Sustainability Objects of Mineral Resources Sector of Russia Journal of Mining Institute 237: $354-360$.

Nevskaya M.A. et al.(2019) Environmental and Business Challenges Presented by Mining and Mineral Processing Waste in the Russian Federation Minerals 9: 445.

Novikov, N.I. \& Salikhov, V.A. 2015. The main directions and prospects for the development of the mineral raw material base of non-ferrous and rare metals in the world and in Russia Bulletin of Tomsk State University 2(30): 138-150.

Paulick, H. \& Machacek, E. 2017. The global rare earth element exploration boom: an analysis of resources outside China and discussion of development perspectives Resource Policy 52: 134-153.

Ponomarenko, T.V., Khan-Tsai, E.A. \& Bavuu Chantsalma. 2019. Integrated mining projects in underdeveloped territories of Russia: substantiation of implementation parameters Journal of Mining institute 240: 724-730.

Ponomarenko, T.V., Nevskaya, M.A. \& Marinina, O.A. 2018. Complex use of mineral resources as a factor of the competitiveness of mining companies under the conditions of the global economy International Journal of Mechanical Engineering and Technology 9: 1215-1223.

Postolateva, A., Tverdov, A \& Zhura, A. 2013. Rare earth deposits - features, complicity and prospects. Gold and technologies 1(19): 33-36.

Rare earth market outlook: supply, demand, and pricing from 2016 through 2025 Adamas Intelligence: Critical Metals and Minerals Research. viewed 12.02.2020 https://1b9dn310cnw45swh730g66pj-wpen gine.netdna-ssl.com/wp-content/uploads/2018/02/Adamas-Intelligence-Rare-Earth-Market-OutlookDecember-2016-Executive-Summary.pdf.

Samsonov, N.Y. \& Semyagin, I.N. 2014. Overview of the global and Russian rare earth metals market All-Russian ECO journal 44(2): 45-54.

Saveleva, L.I. 2011. The rare-earth metals industry of Russia: Present status, resource conditions of development Geography and Natural Resources 32(1): 65-71.

Scripachev, S.Y. 2018. About the state and prospects of REE industry development Presentation The All-Russian Institute Of Aviation Materials (VIAM).

Solovyova, V.M. \& Cherepovitsyn, A.E. 2019. CUMR projects: Possibilities for implementation on Arctic territories Topical Issues of Rational Use of Natural Resources 2019 doi: 10.1201/ 9781003014638-23.

Takeda, O. \& Okabe, T. 2014. Current Status on Resource and Recycling Technology for Rare Earths The Minerals, Metals \& Materials Society and ASM International 160 doi:10.1007/s40553-014-0016-7.

The development strategy of the rare and rare earth metals industry of the Russian Federation for the period up to 2035. viewed 10.01.2019. http://static.government.ru/media/files/WXRSEBj6jnRWN rumRkDakLcqfAzY14VE.pdf.

Wall, F. 2014. Rare earth elements. In Critical Metals Handbook Hoboken, NJ 312-339.

Zhou, B., Li, Z. \& Chen, C. 2017. Global Potential of Rare Earth Resources and Rare Earth Demand from Clean Technologies Minerals 7(203) doi: 10.3390/min7110203. 